\title{
Seasonal changes in nutrient dynamics and limitation in the P-depleted ultra- oligotrophic Eastern Mediterranean \\ Sea
}

\author{
TAL BEN-EZRA ${ }^{1}$, ANAT TSEMEL ${ }^{1}$, ILANA BERMAN- \\ FRANK $^{2}$ AND MICHAEL DAVID KROM ${ }^{3}$ \\ ${ }^{1}$ Haifa University \\ ${ }^{2}$ University of Haifa \\ ${ }^{3}$ Charney School of Marine Sciences \\ Presenting Author: m.d.krom@leeds.ac.uk
}

The Eastern Mediterranean Sea (EMS) despite being an inland sea, has many of the characteristics of a P depleted oceanic gyre system such as the N.W. Atlantic gyre (e.g. BATS). As a result of its anti-estuarine circulation it is ultra-oligotrophic and picoplankton dominate the autotrophic community. Results from a series of monthly cruises, carried out using an ultra-sensitive nutrient analysis, showed a characteristic nutrient dynamic; In winter, which is also the time of the annual phytoplankton bloom, the photic zone was phosphate depleted while there was excess nitrate present at a concentration of $300-500 \mathrm{nM}$. After the seasonal stratification was established in April, nitrate decreased until it became depleted in nitrate by mid-simmer into autumn. Dissolved organic phosphorus (DOP) was also unusually low (30-40nM) with only minor seasonal changes. This seasonal nutrient dynamic seems to be characteristic of $\mathrm{P}$ depleted oceanic systems.

Nutrient limitation is a key parameter in controlling primary productivity and carbon uptake in such seasonally changing ocean systems. In this study we have developed and used a new method for determining the limiting nutrient. This method involves a $5 \times 5$ matrix of nutrient $(\mathrm{N} \& \mathrm{P})$ additions and the determination of 2 endpoints simultaneously; Chlorophyll a is used as a proxy to define the limiting nutrient for the autotrophic community and an Alkaline Phosphatase activity (APA) endpoint in which the entire microbial community responds to the presence/absence of inorganic phosphate by producing or suppressing APA. Our results showed that in late summer, when the system was both phosphate and nitrate depleted, the autotrophs became N\&P co-limited $->\mathrm{N}$ limited while the heterotrophs were $\mathrm{P}$ limited. Results for winter and spring will be presented and the probably reasons for these seasonally changing pattern in nutrient limitation will be discussed. 